\title{
ANALYTICAL STUDY OF LITERACY \& SOCIOECONOMIC STATUS OF PATIENTS REGISTERED FOR TREATMENT UNDER RNTCP DOTS CATEGORY II
}

\author{
Ansar Alam¹, Ravi Dosi², Ravindra Chordiya3 ${ }^{3}$, Satish Motiwale4, R. K. Jha5, Ashok Bajpai6
}

\section{HOW TO CITE THIS ARTICLE:}

Ansar Alam, Ravi Dosi, Ravindra Chordiya, Satish Motiwale, R. K. Jha, Ashok Bajpai. "Analytical Study of Literacy \& Socioeconomic Status of patients registered for treatment under RNTCP DOTS Category II". Journal of Evolution of Medical and Dental Sciences 2014; Vol. 3, Issue 06, February 10; Page: 1553-1560,

DOI: $10.14260 /$ jemds/2014/2023

\begin{abstract}
Tuberculosis remains a prominent cause of social stigma and is predominantly associated with lower socio economic strata and illiteracy. Predominantly male subjects were identified in both RNTCP \& Non RNTCP groups with non RNTCP groups comprised mostly of the literate and higher socio economic strata \& RNTCP groups of the literate and lower socio economic population. The female population of the RNTCP group was predominantly illiterate and from the lower socio economic strata
\end{abstract}

KEYWORDS: Tuberculosis , MDR , Literacy

INTRODUCTION: Tuberculosis is one of the oldest and most prevalent diseases in our country and about $40 \%$ of the population in India is estimated to be infected with Mycobacterium Tuberculosis. Tuberculosis is a major public health priority in the world with 8-10 million new cases added every year ${ }^{1}$.

Tuberculosis is a barrier to socio-economic development. The greatest burden of Tuberculosis incidence \& mortality in India is in adults which include the most productive members of the society. Tuberculosis affects more males than females and the prevalence of disease increases with age ${ }^{2}$.

The five countries with the largest number of incident cases in 2011 were India (2.0 million2.5 million), China (0.9 million-1.1 million), South Africa (0.4 million-0.6 million), Indonesia (0.4 million-0.5 million) and Pakistan (0.3 million-0.5 million). India and China alone accounted for 26\% and $12 \%$ of global cases, respectively 3 .

\section{AIMS \& OBJECTIVES:}

1. To obtain information about literacy in patient's registered as re-treatment cases in RNTCP Program at Sri Aurobindo Medical College \& Post Graduate Institute, Indore.

2. To obtain information about socioeconomic status of patient's registered as re-treatment cases in RNTCP Program at Sri Aurobindo Medical College \& Post Graduate Institute, Indore.

\section{MATERIAL \& METHODS:}

RESEARCH DESIGN: This is a longitudinal prospective observational study.

STUDY SET UP: The study was conducted in the Department of Respiratory Medicine at Sri Aurobindo Medical College and Post Graduate Institute, Indore (M. P.). 
STUDY DURATION: The duration of study was 20 months from October-2011 to May-2013.

SAMPLING: Simple Random Sampling Technique was used for selection of desired samples according to inclusion criterion.

\section{INCLUSION CRITERIA:}

I. Diagnosed cases of Pulmonary Tuberculosis who have been registered in RNTCP as retreatment cases under DOTS centre Sri Aurobindo Medical College \& Post Graduate Institute.

II. Age group more or equal to 18 yrs.

\section{EXCLUSION CRITERIA:}

I. Patients suffering from Extra Pulmonary Tuberculosis

II. Critically ill patient.

III. Pulmonary Tuberculosis with Human Immunodeficiency Virus

IV. Patient unwilling for study

\section{STUDY TOOLS:}

V. Complete hemogram

VI. Erythrocyte Sedimentation Rate

VII. Sputum for Acid Fast Bacilli(2 samples)

VIII. Sputum for Acid Fast Bacilli culture \& sensitivity

IX. Aspartate aminotransferase

X. Alanine aminotransferase

XI. Random Blood Sugar

XII. Serum Creatinine

METHODOLOGY: The patient who was diagnosed as a case of pulmonary Tuberculosis sputum positive attending the OPD, IPD and are registered for re-treatment cases under DOTS center SAMC \&PGI.

A total no of 100 patients of re-treatment cases who gave oral informed consent were registered as subjects.

STATISTICAL TECHNIQUE: The raw data of 100 subjects were entered into the computer database and responses of frequencies were calculated and analyzed by using statistical software, SPSS version 16.0. Prevalence of an outcome variable along with 95\% confidence limits was calculated. Information about sources of previous drug exposure for patients registered as re-treatment had been identified. Both, descriptive and inferential statistics were used to study the "ROLE OF SOURCES AND TYPE OF PREVIOUS TUBERCULOSIS DRUG EXPOSURES FOR PATIENTS REGISTERED IN RNTCP AS RE-TREATMENT CASES".

Descriptive statistical analysis has been used to depict the main features and characteristic of the collected samples to identify the previous drug exposure with major reasons for defaulting treatment for Tuberculosis. Results on categorical measurements are presented in numbers (\%) while results on continuous measurements are presented on Mean \pm SD (Min-Max). 
Unpaired t-test has been also used to observe the significance of mean difference of study parameters and LFT on continuous scale to explore the causes of drug resistance between subjects selected from RNTCP (DOTS) and Non RNTCP.

The Non-parametric test, Pearson's Chi-Square test has been used for qualitative data to observe the association of parameters between RNTCP (DOTS) and Non RNTCP so that major reasons for defaulting treatment for Tuberculosis had identified and that further used to explore the causes of drug resistance.

\section{SIGNIFICANT PROBABILITY FIGURES:}

+Suggestive/Poor significance ( $p$ value: $0.05<\mathrm{p}<0.10$ )

${ }^{*}$ Moderately significant ( $\mathrm{p}$ value: $0.01<\mathrm{p}<0.05$ )

${ }^{* *}$ Highly/Strongly significant ( $p$ value: $0.01<p<0.001$ )

This study dealt with 100 cases of Tuberculosis drug exposures out of which $68.0 \%$ of the subjects were from RNTCP group $\$ 32.0 \%$ of the subjects were selected from Non RNTCP group.

Age:

- The mean age for the subjects chosen from RNTCP group was $45.31 \pm 17.06$ years.

- The mean age for the subjects chosen from RNTCP group was 39.81 \pm 14.02 years.

- The maximum numbers of subjects in this study (25.0\%) were from the age group between 28-37 years.

\section{Sex distribution:}

\section{Male Subset}

Total Male subjects -82

$76.5 \% \rightarrow$ RNTCP group

$93.8 \% \rightarrow$ Non RNTCP group

\section{Female Subset:}

Total Female subjects - 18

$23.5 \% \rightarrow$ RNTCP group

$6.2 \% \rightarrow$ Non RNTCP group

\section{EDUCATIONAL STATUS:}

\section{RNTCP}

Educated -

Male $\rightarrow 36.7 \%$

Female $\rightarrow 5.8 \%$

Uneducated -

Male $\rightarrow 39.7 \%$

Female $\rightarrow 17.6 \%$ 


\section{ORIGINAL ARTICLE}

\section{Non RNTCP}

Educated

Male $-40.65 \%$

Female $-3.1 \%$

Uneducated

Male - 53.125\%

Female $-3.1 \%$

- Highest literacy was seen in RNTCP male subjects $\rightarrow 36.76 \%$

- Highest illiteracy was seen in RNTCP male subjects $\rightarrow 39.7 \%$

- Higher rate of illiteracy $44 \%$ as compared to $38 \%$ is seen in study patients.

\section{SOCIO-ECONOMIC STATUS OF SUBJECTS:}

\section{Monthly income less than rupees 5000/-}

Non RNTCP - 78.1\%

RNTCP - 76.5\%

Monthly income rupees 5000/- to 10000/-

Non RNTCP - $12.5 \%$

RNTCP - 16.2\%

\section{Monthly income more than rupees 10000/-}

Non RNTCP - 9.4\%

RNTCP - 7.4\%

- Most of the subjects enrolled in the group were in the lower socio economic group

- Subjects from higher socio economic groups preferred Non RNTCP group

DISCUSSION: The change over from fully supervised sanatorium treatment to unsupervised domiciliary treatment has affected compliance significantly. ${ }^{4}$ Poor compliance with treatment is also an important factor in the development of acquired drug resistance. In a study conducted in South India it was that only $43 \%$ of the patients receiving short course treatment $(n=2306)$ and $35 \%$ of those receiving standard chemotherapy $(\mathrm{n}=1051)$ completed $80 \%$ or more of their treatment.5-9

Non-compliance with prescribed treatment is often underestimated by the physician and is difficult to predict. The drug defaulter, just like placebo reactor is not a consistent or readily identified person. In the west, demographic factors such as age, sex, marital status, education level and socioeconomic status have not been found to correlate with the degree of compliance. On the other hand, certain factors such as psychiatric illness, alcoholism, drug addiction and homelessness have been found to strongly predict non-compliance ${ }^{10,11}$. These may not be entirely true in the Indian context and the relevance of these factors in the Indian scenario merits further study.

Considering the changing epidemiological scenario DOTS is presently being advocated by the WHO to be the only effective way to control Tuberculosis ${ }^{5-7}$. However DOTS has not been adopted 
universally and the control program in several parts of the world are chaotic and adherence is very poor due to the high prevalence of addiction and tobacco related complications 8 .

Santha et al ${ }^{11,12}$ studies the risk factors associated with default, failure and death among Tuberculosis patients treated in a newly implemented DOTS program in south India. In this study, 676 patients were registered during the one year study period. In multi variant analysis, higher defaulter rates were associated with irregular treatment and high incidence of tobacco addiction. ${ }^{11}$

\section{RESULTS:}

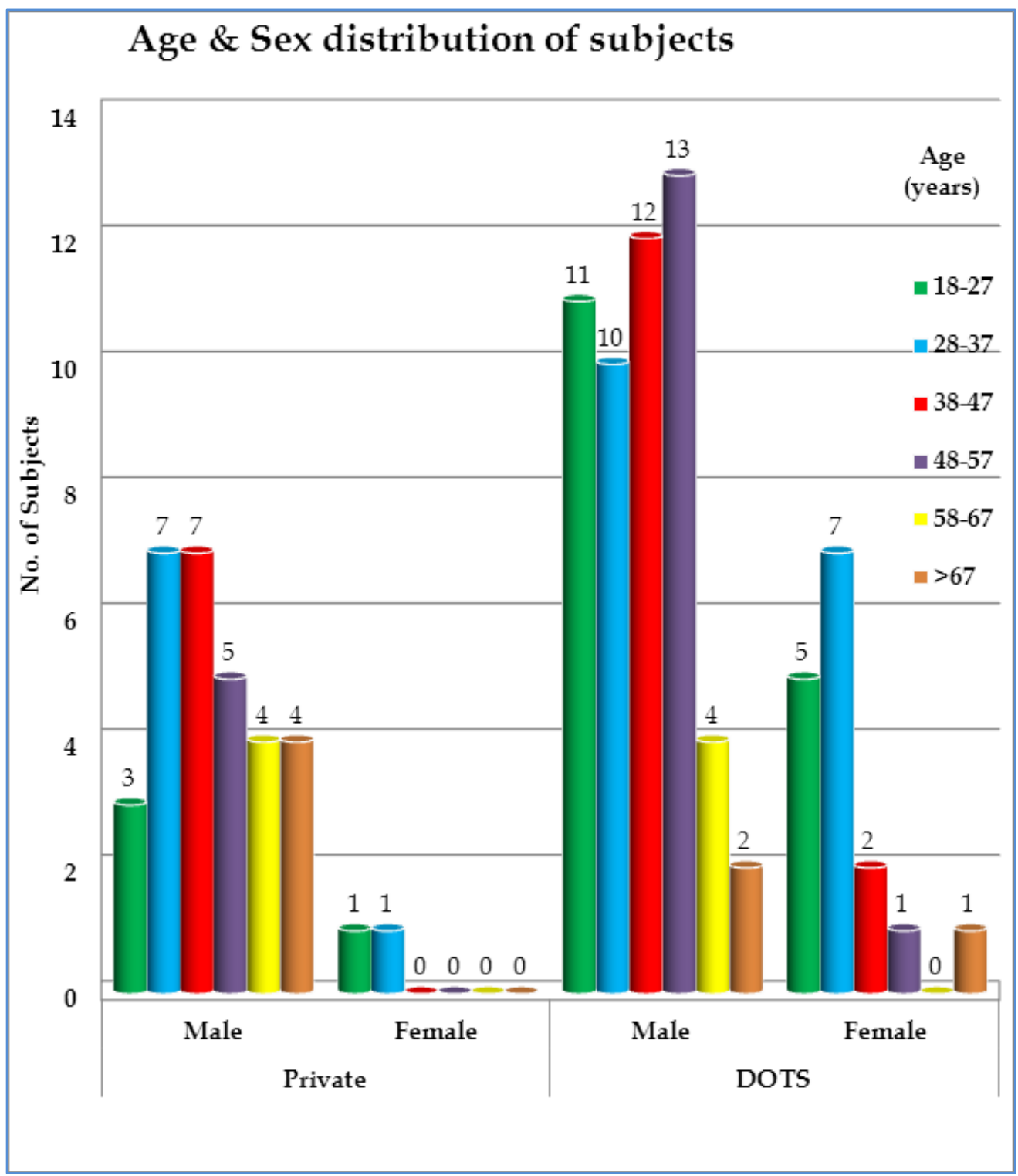




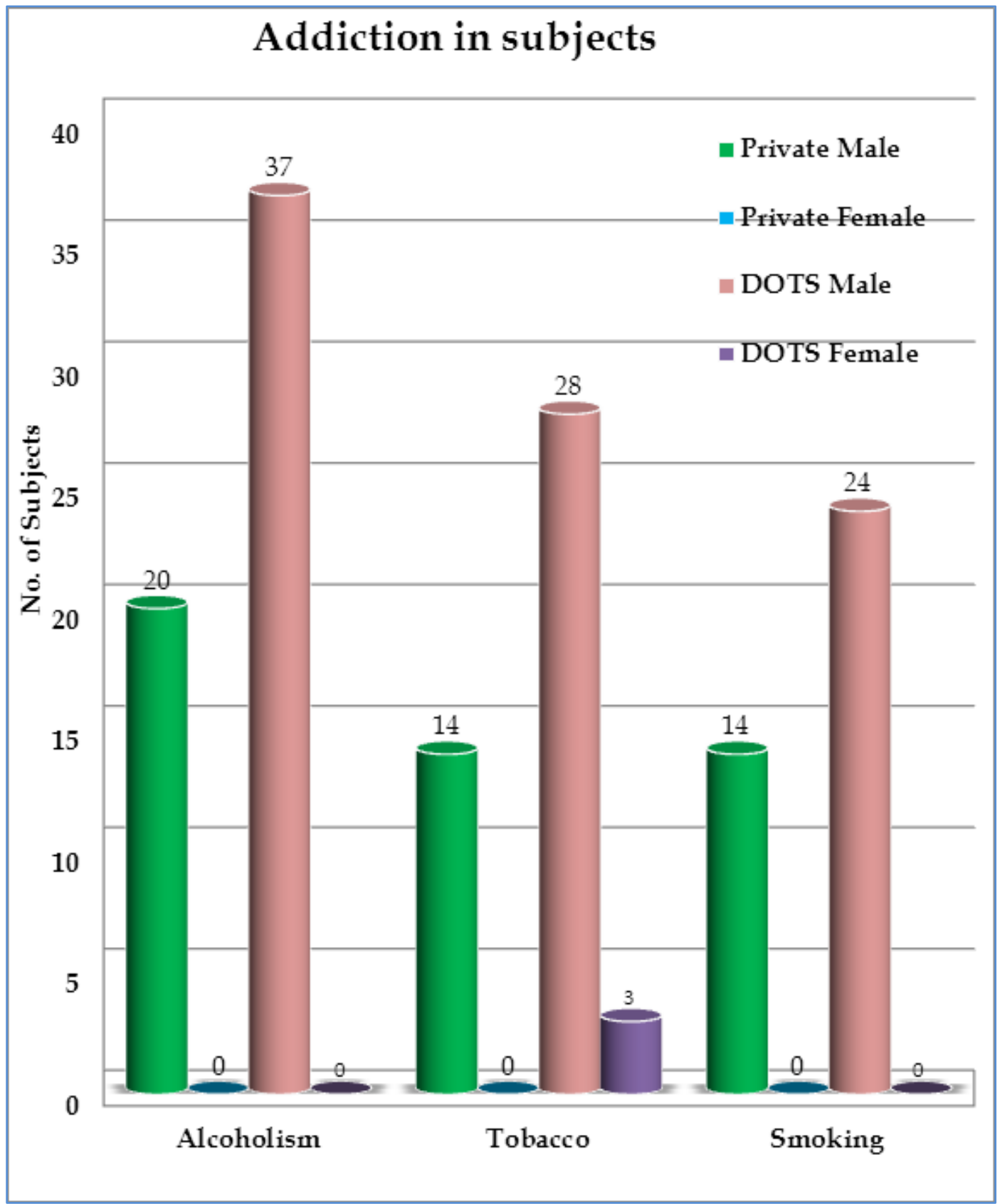

Fig. 2-Bar graph showing comparison of addiction among selected subjects from private \& DOTS 


\section{REFERENCES:}

1. Mitter, B. Schieffelbein, C. Tuberculosis; Bulletin of the World Health Organization 1998, 76(suppl.2)141.

2. Sivaraman S. Tuberculosis in India: the prospects Indian Journal of Tuberculosis, 1999, 46, 81.

3. http://www.who.int/tb/publications/global_report/gtbr12_main.pdf page no11

4. World Health Organization. Tuberculosis fact sheet. Available from URI:http://www.who.int/gTuberculosis/publication/factsheet/index.htm. Accessed on 1 July 2003.

5. Freiden TR. Direct Observed Therapy short course: the strategy that ensures cure of Tuberculosis. New Delhi: JayPee brothers medical Publishers 2001p 536-46.

6. Khatri GR, Frieden TR. Controlling Tuberculosis in India. New England Journal Med 2002:347:1420-5 India. N Engle J med 2002:347:1420-25.

7. Bastin me, Rigouts L, Van Dcun A, Portaels F. Directly observed treatment, short course strategy and multi drug resistant Tuberculosis are any modifications required? Bull World Health Organization 2000:78:238-51.

8. Teklu B. Reasons for failure in treatment of pulmonary Tuberculosis in Ethiopians. Tubercle 1984; 65:17-21.

9. Blackwell B. Drug therapy: patient compliance. N Engl J Med 1973; 289:249-52.

10. Weis SE, Slocum PC, Blais FX, King B, Nunn M. Matney GB, et al. The effects of directly observed therapy on the rates of drug resistance and relapse in Tuberculosis. N Engl J Med 1994; 330:1179-84.

11. Santha T, Garg R, Frieden TR, Chandrashekharan V. Subbramanium R, Gopi PG, et al. Risk factors associated with default, failure and death among Tuberculosis patients treated in a DOTS programme in Triuvallur district, South India, 2000. Int J Tuberc Lung Dis 2002; 6:780-8. 


\section{AUTHORS:}

1. Ansar Alam

2. Ravi Dosi

3. Ravindra Chordiya

4. Satish Motiwale

5. R. K. Jha

6. Ashok Bajpai

\section{PARTICULARS OF CONTRIBUTORS:}

1. Post Graduate, Department of Respiratory Diseases, Sri Aurobindo Institute of Medical Sciences \& Post Graduate Institute, Indore.

2. Assistant Professor, Department of Respiratory Medicine, Sri Aurobindo Institute of Medical Sciences \& Post Graduate Institute, Indore.

3. Professor, Department of Respiratory Medicine,Sri Aurobindo Institute of Medical Sciences \& Post Graduate Institute, Indore.

4. Associate Professor, Department of Respiratory Medicine,Sri Aurobindo Institute of Medical Sciences \& Post Graduate Institute, Indore.
5. Professor, Department of General Medicine, Sri Aurobindo Institute of Medical Sciences \& Post Graduate Institute, Indore.

6. Professor, Department of Respiratory Medicine,Sri Aurobindo Institute of Medical Sciences \& Post Graduate Institute, Indore.

\section{NAME ADDRESS EMAIL ID OF THE CORRESPONDING AUTHOR:}

Dr.Ravi Dosi,

124, Tilak Nagar,

Main Post Office Road,

Indore - 452018, M.P. [INDIA].

E-mail: ravi.dosi@gmail.com

Date of Submission:06/01/2014.

Date of Peer Review: 07/01/2014.

Date of Acceptance: 28/01/2014.

Date of Publishing: 10/02/2014. 